\title{
Vertical Temperature Structure Associated with Evaporation of Stratiform Precipitation in Idealized WRF Simulations
}

\author{
M. Virman, M. Bister, V. A. Sinclair, J. RÄISÄNEN, AND H. JÄRVINEN \\ Institute for Atmospheric and Earth System Research/Physics, Faculty of Science, University of Helsinki, Helsinki, Finland
}

(Manuscript received 25 April 2019, in final form 28 February 2020)

\begin{abstract}
A recent study based on observations has shown that after precipitation over tropical oceans rather shallow temperature structures occur in the lower troposphere and that their magnitude depends on climatological low- to midtropospheric humidity. As any process that produces temperature perturbations in the lower troposphere can be of great significance for the formation of atmospheric deep convection, the vertical temperature structure associated with evaporation of stratiform precipitation and its sensitivity to low- to midtropospheric humidity are studied by conducting three-dimensional, high-resolution, idealized simulations with the Advanced Research version of the Weather Research and Forecasting (WRF) Model. In the simulations, rainwater with mixing ratio and number concentration characteristic of stratiform precipitation associated with mesoscale convective systems is added in a large round area at roughly $560 \mathrm{hPa}$. Evaporative cooling and subsidence warming below result in a cold anomaly at roughly $560-750 \mathrm{hPa}$ and, especially, a warm anomaly at roughly $750-900 \mathrm{hPa}$. The cold-over-warm anomalies are stronger with smaller low- to midtropospheric relative humidity in the initial conditions, with the maximum magnitude of the warm anomaly ranging between 0.7 and $1.2 \mathrm{~K}$. The temperature anomalies propagate to the environment and still remain present after precipitation stops. The results show that evaporation of stratiform precipitation alone can lead to temperature structures, which are on the same order of magnitude as the observed ones, that potentially inhibit subsequent convection by increasing convective inhibition. Therefore, the representation of microphysical processes affecting the location, amount, and vertical and horizontal distribution of stratiform precipitation and its evaporation in numerical models requires special attention.
\end{abstract}

\section{Introduction}

The majority of precipitation over tropical oceans is associated with mesoscale convective systems (MCSs; Rickenbach and Rutledge 1998), which produce both stratiform and convective precipitation (e.g., Houze 2018). The vertical heating profile associated with MCSs over the moistest regions of tropical oceans has been shown to be positive at all altitudes with its maximum in the upper troposphere (e.g., Houze 1982). The heating associated with MCSs strongly influences the vertical structure of temperature in their near environment, but not in a simple way (Mapes 1993; Mapes and Houze 1995). For example, Mapes and Houze (1995) studied temperature structures near an imposed heat source characteristic of mature MCSs over the moistest regions of tropical oceans by using an idealized model. They found that close to the original positive-only heat source

\footnotetext{
Corresponding author: M. Virman, meri.virman@helsinki.fi
}

there was a warm anomaly in the upper troposphere above the $\sim 500-\mathrm{hPa}$ level, and a cold anomaly in the whole lower troposphere below the $\sim 500$-hPa level. In some cases, a shallow warm anomaly above the boundary layer has been observed in association with tropical MCSs, particularly squall lines (Zipser 1969, 1977; Johnson and Kriete 1982; Johnson 1986).

A recent study by Virman et al. (2018) showed that the vertical temperature structures observed after precipitation over tropical oceans were different over stations with different climatological relative humidity $(\mathrm{RH})$ between 500 and $700 \mathrm{hPa}$. In the observations, the vertical structure of the temperature anomalies in the moistest regions resembled that which formed close to the imposed MCS heat source in simulations of Mapes and Houze (1995), with a cold anomaly in the whole lower troposphere. In contrast, Virman et al. (2018) found that in the driest regions a warm anomaly, at $\sim 800-950 \mathrm{hPa}$, was observed below a cold anomaly, suggesting that the vertical profile of heating is not 
similar over the moist and dry regions. As evaporation is the diabatic process through which lower-freetropospheric moisture can most efficiently affect the vertical profile of heating (and therefore the resulting temperature anomalies), evaporation of stratiform precipitation could be the reason for the different temperature anomaly structures.

The amount of lower-free-tropospheric moisture or column water vapor has been shown to be a fundamental factor in regulating deep convection (e.g., Brown and Zhang 1997; Sherwood 1999; Sobel et al. 2004; Bretherton et al. 2004; Peters and Neelin 2006; Holloway and Neelin 2009; Neelin et al. 2009). The negative effect of downdrafts on subsequent convection in dry air (see, e.g., Raymond 1995; Tompkins 2001) and, particularly, entrainment of dry environmental air into the convective updrafts (Derbyshire et al. 2004; Holloway and Neelin 2009; Hirons et al. 2013; Schiro et al. 2016) have previously been suggested to explain the sensitivity.

Numerical weather forecasting and climate models still do not realistically represent convective phenomena, especially the Madden-Julian oscillation (MJO), although there has been significant improvements recently (Kim et al. 2011, 2018; Bechtold 2019). It has been noted that improvements in the representation of MJO in atmospheric general circulation model simulations resulted in the degradation of the model mean precipitation, suggesting that the simulated MJO improved for the wrong reasons (Kim et al. 2011, 2018). Moreover, the prediction skill of MJO is sensitive to model physics (Kim et al. 2018). It is therefore possible that the mechanisms responsible for convection's sensitivity to lower-free-tropospheric moisture are not correctly represented in some models.

Any process that increases temperature just above the boundary layer increases convective inhibition (CIN) by decreasing the potential buoyancy of rising air parcels and may therefore inhibit the formation of precipitating convection altogether (Wei et al. 1998; Raymond et al. 2003). Virman et al. (2018) suggested that lower-freetropospheric moisture may affect the formation of new convection also implicitly through the lower-tropospheric temperature changes associated with evaporation of stratiform precipitation. Namely, evaporation of stratiform precipitation and resulting subsidence could, depending on lower-free-tropospheric moisture, cause warm anomalies that potentially prevent the formation of subsequent convection by increasing CIN. Specifically, they hypothesized that in dry air, a warm anomaly forms just above the boundary layer as a result of subsidence warming and weak evaporation occurring below a layer of stronger evaporative cooling [see Fig. 5 of Virman et al. (2018)]. In moist air, on the other hand, the subsidence warming is not sufficient to overcompensate the evaporative cooling just above the boundary layer, resulting in a cold anomaly there. This hypothesis is supported by earlier idealized axisymmetric simulations used to study tropical cyclogenesis (Bister and Emanuel 1997).

It is evident that the temperature structures and, particularly, their association with evaporation of stratiform precipitation require a more detailed analysis. Idealized numerical model simulations are the necessary first step to toward this goal, as it is not possible to isolate the physical processes associated with temperature structures by using only observational datasets. The goal of this study is to quantify the temperature structures associated with evaporation of stratiform-like precipitation and their sensitivities to environmental conditions, particularly, lower-free-tropospheric moisture, by conducting idealized numerical simulations. We also discuss the formation mechanism of the temperature structures. The model and experiment design is presented in section 2. The results from the control simulation, as well as from several sensitivity tests, are shown in section 3. The results are discussed in section 4 and conclusions are provided in section 5 .

\section{Experiment design}

Here we study the temperature response to evaporation of stratiform precipitation by conducting several three-dimensional high-resolution idealized simulations, similar to the highly idealized axisymmetric simulations of Bister and Emanuel (1997). We used the fully compressible, nonhydrostatic, three-dimensional atmospheric Advanced Research version of the Weather Research and Forecasting (WRF) Model, version 3.9 (Skamarock et al. 2008).

In the simulations, stratiform precipitation was artificially added at one model level, below which the precipitation falls freely. The precipitation was added continuously at every time step (after the first time step) for $10 \mathrm{~h}$ in all simulations. The model domain was $1500 \mathrm{~km} \times 1500 \mathrm{~km}$ in size, with the precipitation added to a large round area at the center of the domain (Figs. 1a,b). More specifically, the rain mixing ratio (QR) and number concentration (QNR) were set to $0.2 \mathrm{~g} \mathrm{~kg}^{-1}$ and $1200 \mathrm{~kg}^{-1}$ (per dry air), respectively, within a radius of $0-75 \mathrm{~km}$ from the center, decreasing nonlinearly to zero from 76 to $\sim 100 \mathrm{~km}$ (Figs. 1a,b). The whole precipitation area covered roughly $40000 \mathrm{~km}^{2}$. Roughly $1 \%$ of MCSs over the Maritime Continent exceed this size (Mohr and Zipser 1996). Although the largest MCSs are few in number, they produce a large amount of the total precipitation from all MCSs (Houze 1993). The QR and QNR values correspond to those 

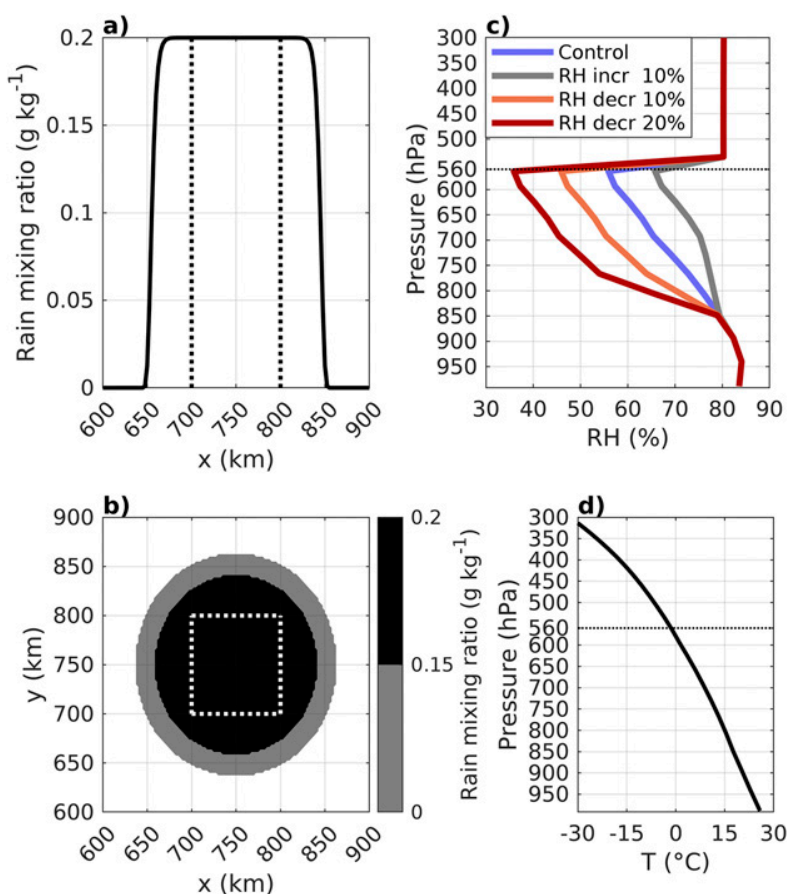

FIG. 1. Distribution of rain mixing ratio at the model level corresponding to roughly $560 \mathrm{hPa}$ (a) in the middle of the model domain and (b) as viewed from above. Only part of the $1500 \mathrm{~km} \times$ $1500 \mathrm{~km}$ model domain is shown in (a) and (b). The area between the dashed lines in (a) and (b) represents the area from which horizontal averages are calculated in Figs. 4, 7, and 8. Note that the color scale in (b) is nonlinear. (c) Vertical profile of initial relative humidity in the control simulation (blue) and when low- to midtropospheric relative humidity is increased by $10 \%$ (gray), decreased by $10 \%$ (orange), and decreased by $20 \%$ (red). (d) Vertical distribution of initial temperature, which corresponds to the moist tropical sounding in Dunion (2011). The dotted line in (c) and (d) represents the level where precipitation is added.

occurring just below the melting level of a stratiform precipitation region of a simulated squall line produced with an idealized setup of WRF as in Morrison et al. (2009). Contrary to MCSs occurring in nature, with all phases of water and the associated microphysical processes present, in our idealized simulations where precipitation is artificially added at one model level, only liquid water that falls and evaporates was included.

The control simulation was initialized with a sounding from Dunion (2011) that is characteristic of a moist tropical climate over ocean. The model level to which precipitation was added is at roughly $560 \mathrm{hPa}$, just above the zero isotherm (Figs. 1c,d). A few modifications were made to the sounding from Dunion to meet the purposes of these simulations. RH was set to $80 \%$ between the model levels located at the roughly $560-120 \mathrm{hPa}$ in all of the model domain (Fig. 1c). This moist layer was included to mimic the anvil cloud from which the stratiform precipitation falls from and to thus prevent too intense evaporation. $\mathrm{RH}$ of $80 \%$ was used because condensation of water vapor occurred with larger values. The Coriolis parameter and horizontal wind at all levels in the initial conditions were set to zero because the goal of the simulations is to identify the temperature structures associated with evaporation of stratiform precipitation, without any other complicating factors. The initial state was approximately in hydrostatic balance. The surface was all ocean and surface fluxes were switched off to prevent the development of convection.

There were 65 vertical levels between the surface and the model top, which was at $27 \mathrm{~km}$, with about 400 $500 \mathrm{~m}$ between each level depending on the altitude. Rayleigh damping was applied in the highest $5000 \mathrm{~m}$ with a damping coefficient of $0.003 \mathrm{~s}^{-1}$. The lateral boundary conditions were open. The large model domain and number of vertical levels were chosen to minimize the effect of reflection from the horizontal and top boundaries. A horizontal grid spacing of $2.5 \mathrm{~km}$ was used and the results were not significantly altered when using a smaller grid spacing. The time step was set to $15 \mathrm{~s}$. Similar results were produced with a smaller time step. Horizontal and vertical diffusion in physical space was conducted using a 1.5-order TKE closure. Additionally, the sixth-order numerical diffusion scheme was used with a diffusion factor of 0.12 to reduce finescale noise; however, this had a negligible effect on the results.

The radiative and convective schemes were switched off and the boundary layer and surface layer schemes were the Yonsei University (YSU) scheme (Hong et al. 2006) and the revised MM5 Monin-Obukhov scheme (Jiménez et al. 2012), respectively. For the microphysics scheme, we used the Morrison double-moment bulk scheme (Morrison et al. 2009). Freezing of liquid water was inhibited.

\section{Results}

\section{a. Control simulation}

After $2 \mathrm{~h}$ of the simulation, the following temperature anomalies with respect to the initial temperatures occurred in the whole cylinder containing precipitation (i.e., the volume below the round area precipitation was added to): cold anomalies at $\sim 560-750 \mathrm{hPa}$, warm anomalies at $\sim 750-900 \mathrm{hPa}$ and cold anomalies below the $\sim 950-\mathrm{hPa}$ level (Fig. 2a). Cooling associated with evaporation $\left(\sim 0-1.2 \times 10^{-8} \mathrm{~kg} \mathrm{~kg}^{-1} \mathrm{~s}^{-1}\right.$ in magnitude $)$ produced the cold anomaly at $\sim 560-750 \mathrm{hPa}$ and resulted in subsidence $\left(\sim 1-12 \mathrm{~cm} \mathrm{~s}^{-1}\right.$ in magnitude) of the evaporatively cooled air (Figs. 2b,c). At $\sim 750-900 \mathrm{hPa}$, adiabatic subsidence warming overcompensated evaporative cooling resulting in a warm anomaly there whereas 

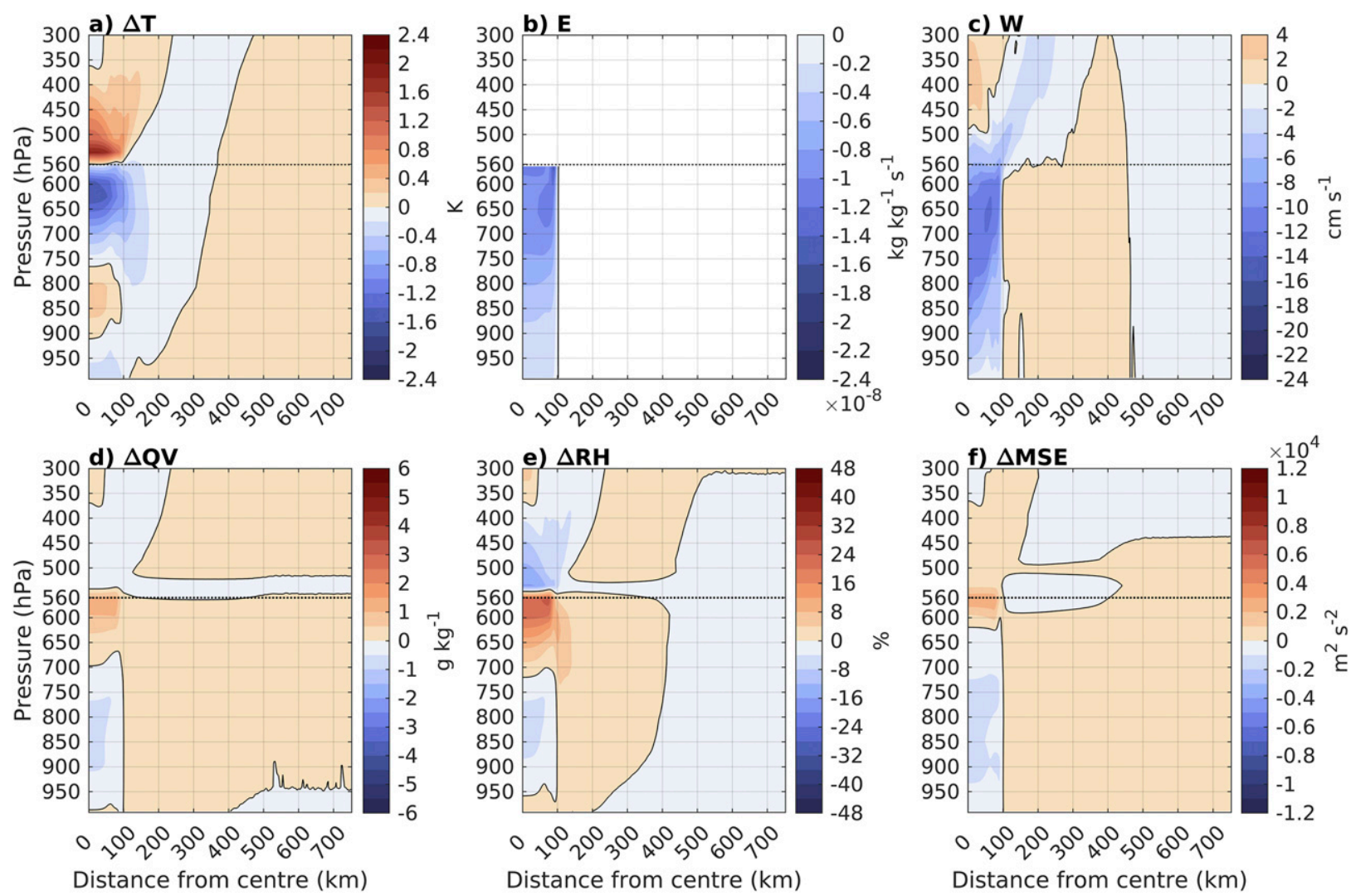

FIG. 2. Vertical cross sections from the center to the edge of the model domain at $2 \mathrm{~h}$ into the control simulation of (a) temperature anomaly, (b) instantaneous evaporation rate, (c) vertical velocity, (d) water vapor mixing ratio anomaly, (e) relative humidity anomaly, and (f) moist static energy anomaly. Anomalies are calculated with respect to initial values. The vertical cross sections are taken from the middle of the model domain. Note that the results are symmetric with respect to $x$. The zero contour is marked in black. The dotted horizontal line indicates the level where precipitation is added.

evaporative cooling collocated with only weak subsidence produced the cold anomaly near the surface (Figs. 2a-c). Evaporation of precipitation resulted in a moist anomaly at $\sim 560-700 \mathrm{hPa}$ (Figs. $2 \mathrm{~d}, \mathrm{e}$ ). Below this, a dry anomaly formed below the $\sim 700$-hPa level due to subsidence of dry (smaller water vapor mixing ratio; not shown) air from above and weak evaporation (Fig. 2d). Negative anomalies of moist static energy (MSE) occurred below the $\sim 620$-hPa level (Fig. 2f).

After $10 \mathrm{~h}$ of simulation (Fig. 3a), the warm anomaly in the cylinder containing precipitation was stronger and deeper and the cold anomaly above it was weaker and shallower, than at $2 \mathrm{~h}$ (Fig. 2a). The larger moist anomaly at $\sim 560-700 \mathrm{hPa}$ resulted in weaker evaporation there, whereas the stronger dry anomaly together with more precipitation available for evaporation (not shown) below the $\sim 700$-hPa level led to stronger evaporation there (Figs. 3b,d,e). Cold anomalies and warm anomalies occurred also outside of the cylinder containing precipitation (Fig. 3a). A warm anomaly occurred in the lower troposphere close to the cylinder containing precipitation and a weak cold anomaly occurred closer to the edges of the model domain (Fig. 3a).

One of the reviewers pointed out a near-surface (roughly $900-950 \mathrm{hPa}$ ) warm anomaly resembling a heat burst (Johnson 2001) occurring at the edge of the region with evaporation (Fig. 3a). Indeed, nonhydrostatic disturbances can form in that region. The strong local warming was therefore likely due to air parcels having enough kinetic energy to penetrate a layer where they were warmer than the environment.

\section{b. Sensitivity to initial relative humidity}

To test how the initial dryness of air into which the stratiform precipitation falls affects the vertical temperature structure, the initial $\mathrm{RH}$ of the control simulation was, first, increased by $10 \%$, second, decreased by $10 \%$ and, third, decreased by $20 \%$ in the low to midtroposphere (Fig. 1c). The difference between the low- to midtropospheric $\mathrm{RH}$ in the driest and moistest simulation corresponded roughly to the difference between the low- to midtropospheric climatological RH of 

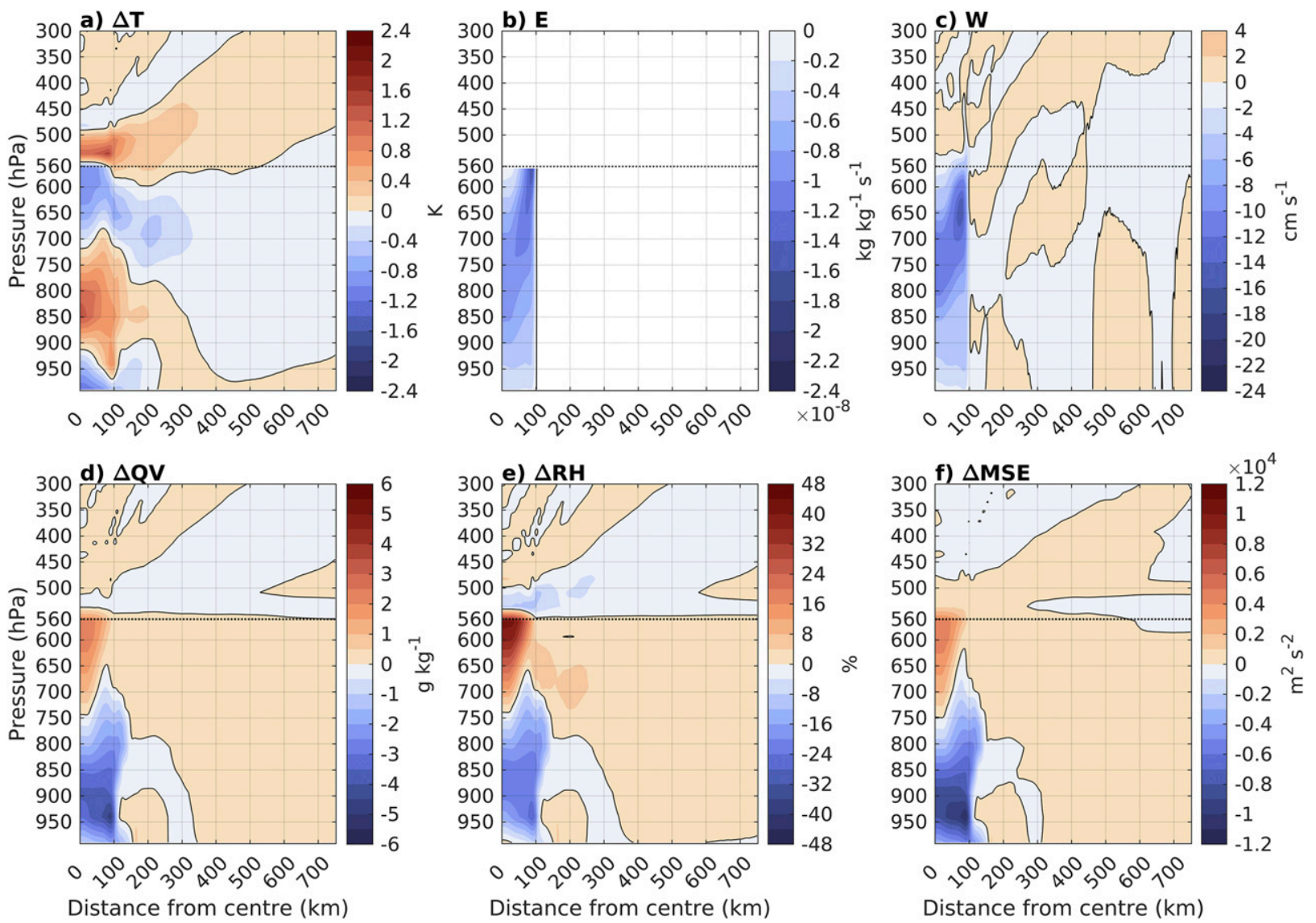

FIG. 3. As in Fig. 2, but at $10 \mathrm{~h}$ into the control simulation.

the driest and moistest sounding stations in Virman et al. (2018).

Horizontally averaged temperature anomalies are now considered (Fig. 4a). These were calculated for each level from a square-shaped area extending to $50 \mathrm{~km}$ from the center of the model domain in both directions with respect to $x$ and $y$. The horizontal means were calculated from a smaller area than the precipitation area to avoid the effect of strong evaporation at the edges of the precipitation area.

The magnitude of the horizontal mean $\sim 560-750-\mathrm{hPa}$ cold and $\sim 750-900-\mathrm{hPa}$ warm anomalies increased quasi linearly from the moistest to the driest simulation (Figs. $4 \mathrm{a}-\mathrm{c}$ ) at all times. The layer containing a warm anomaly as well as the maximum of the warm anomaly was roughly $50 \mathrm{hPa}$ lower in the driest simulation compared to the moistest simulation, extending to $\sim 940 \mathrm{hPa}$ in the driest simulation (Fig. 4c). The magnitude of the horizontal mean warm anomaly exceeded $1.2 \mathrm{~K}$ in the driest simulation at $6 \mathrm{~h}$, which was roughly $0.5 \mathrm{~K}$ more than in the moistest simulation (Fig. 4b). Additionally, the horizontally averaged $\sim 560-700$-hPa moist anomaly and the dry anomaly below the $\sim 700-\mathrm{hPa}$ level were stronger in the drier simulations than in the moister simulations (Figs. 4d-f). The temperature and moisture anomalies were stronger when precipitation fell to drier air as a result of stronger evaporative cooling and resulting stronger subsidence warming (not shown).

Virtual temperature anomalies were calculated for the different sensitivity tests using equations in Emanuel (1994). As expected, the cold and warm anomalies in terms of virtual temperature were weaker compared to temperature (Figs. 4g-i). The strong moist anomalies at $\sim 560-700 \mathrm{hPa}$ and dry anomalies below the $\sim 700-\mathrm{hPa}$ level contributed negatively to the $\sim 560-750-\mathrm{hPa}$ negative and $\sim 750-900-\mathrm{hPa}$ positive virtual temperature anomalies, respectively. Nevertheless, horizontal mean positive virtual temperature anomalies exceeding $0.9 \mathrm{~K}$ were observed after $10 \mathrm{~h}$ (Fig. 4i) of the driest simulation at $\sim 850 \mathrm{hPa}$.

\section{c. Temperature anomalies after precipitation stops}

To study the prevalence of the lower-tropospheric warm anomalies after precipitation stops, QR and QNR were set to zero at $10 \mathrm{~h}$ in the control and driest simulation. For the first $10 \mathrm{~h}$ of these simulations, precipitation 

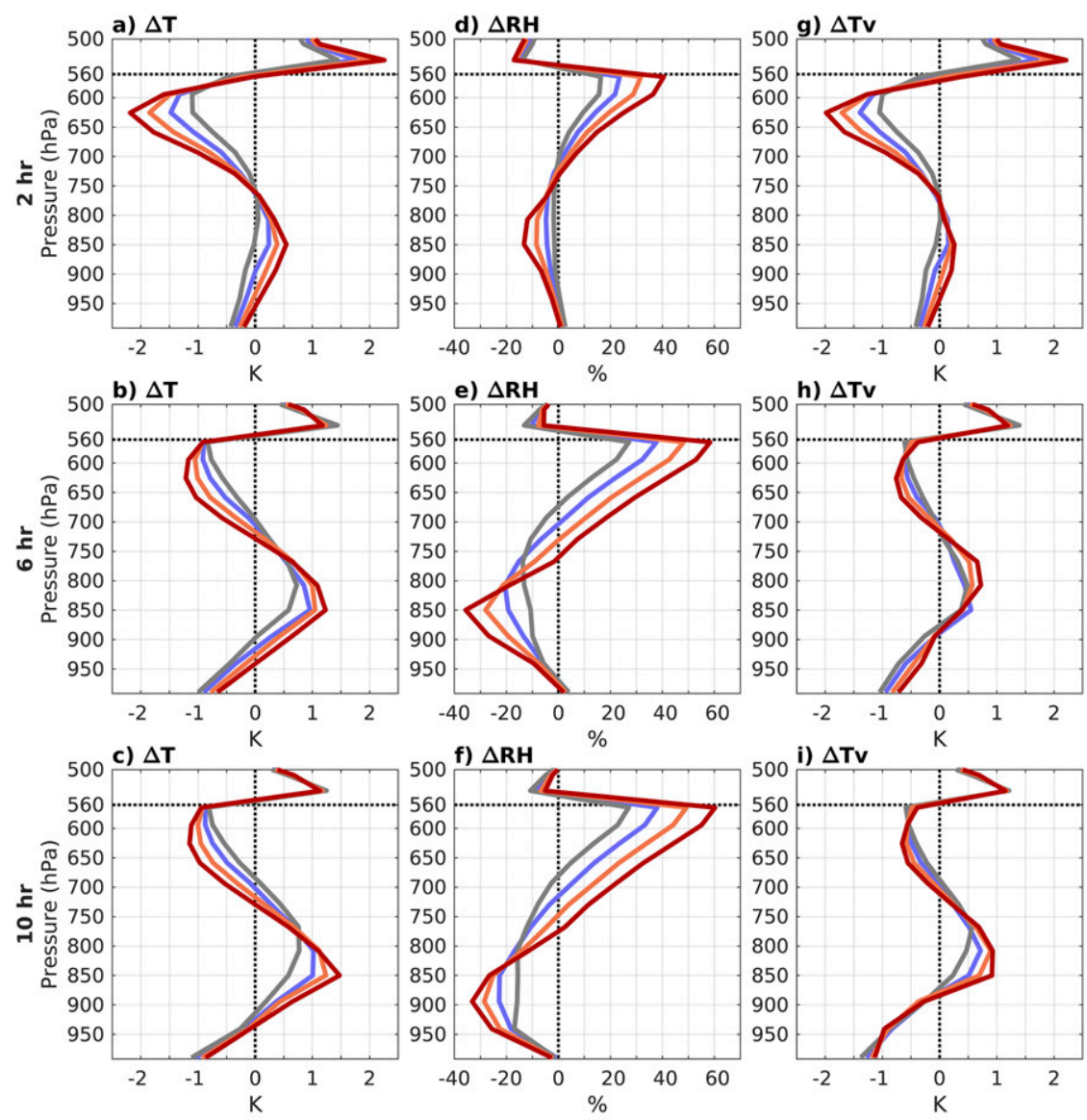

- Control - RH incr $10 \%-$ RH decr $10 \%-$ RH decr $20 \%$

FIG. 4. Horizontally averaged vertical profiles of (a)-(c) temperature anomalies, (d)-(f) relative humidity anomalies, and (g)-(i) virtual temperature anomalies at (top) 2, (middle) 6 , and (bottom) $10 \mathrm{~h}$ into the simulation. The vertical profiles are shown for the control simulation (blue) and when low- to midtropospheric relative humidity is increased by $10 \%$ (gray), decreased by $10 \%$ (orange), and decreased by $20 \%$ (red). The horizontal mean is calculated for each level from a square-shaped area extending to $50 \mathrm{~km}$ from the center of the area containing precipitation in both directions with respect to $x$ and $y$. The dotted horizontal line represents the level where precipitation is added.

was continuously added at each time step (see section 2). The simulations described in this section were continued until $24 \mathrm{~h}$ of total simulation time.

Lack of evaporation in still subsiding air led to a stronger and deeper warm anomaly $40 \mathrm{~min}$ after precipitation stopped compared to when there was still precipitation, that is, at $10 \mathrm{~h}$ of simulation (Figs. 5a-c). A warm anomaly with magnitude up to $2 \mathrm{~K}$ occurred at the $\sim 850-\mathrm{hPa}$ level in the cylinder that previously contained precipitation. A moist and dry anomaly, and positive and negative MSE anomaly, similar to those before precipitation stopped still occurred at $\sim 560-700 \mathrm{hPa}$ and below the $\sim 700$-hPa level, respectively (Figs. $5 \mathrm{~d}-\mathrm{f}$ ).

Warm anomalies at the $\sim 850$-hPa level occurred also far from the center of the precipitation area (Figs. 5a and 6a).
Four hours after precipitation stopped, warm anomalies up to $0.7 \mathrm{~K}$ at the $\sim 850-\mathrm{hPa}$ level still occurred over $100 \mathrm{~km}$ (40 grid points) from the edge of the cylinder that previously contained precipitation (Fig. 6a). Moreover, the warm anomaly was stronger in the driest simulation (Fig. 6b) than in the control simulation (Fig. 6a) after precipitation stopped. The warm anomaly in the driest simulation had a magnitude exceeding $0.8 \mathrm{~K}$ in the cylinder that previously contained precipitation and exceeded $0.4 \mathrm{~K}$ approximately $300 \mathrm{~km}$ from the edge of the cylinder $8 \mathrm{~h}$ after precipitation stopped (Fig. 6b).

\section{d. Other sensitivity tests}

In addition to investigating the effect of initial $\mathrm{RH}$ on the temperature and humidity structures (section $3 \mathrm{~b}$ ), 

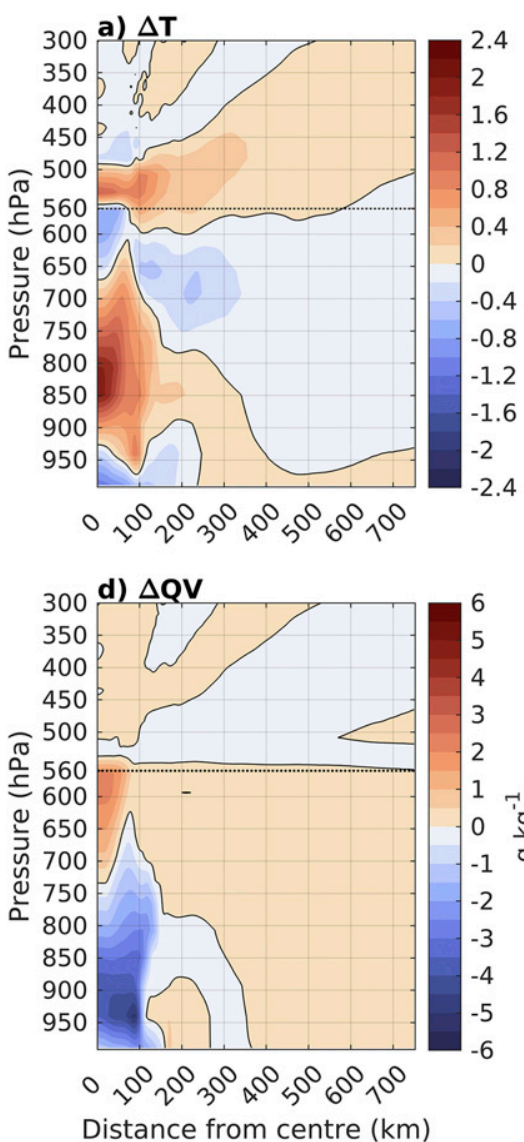

b) $\mathbf{E}$
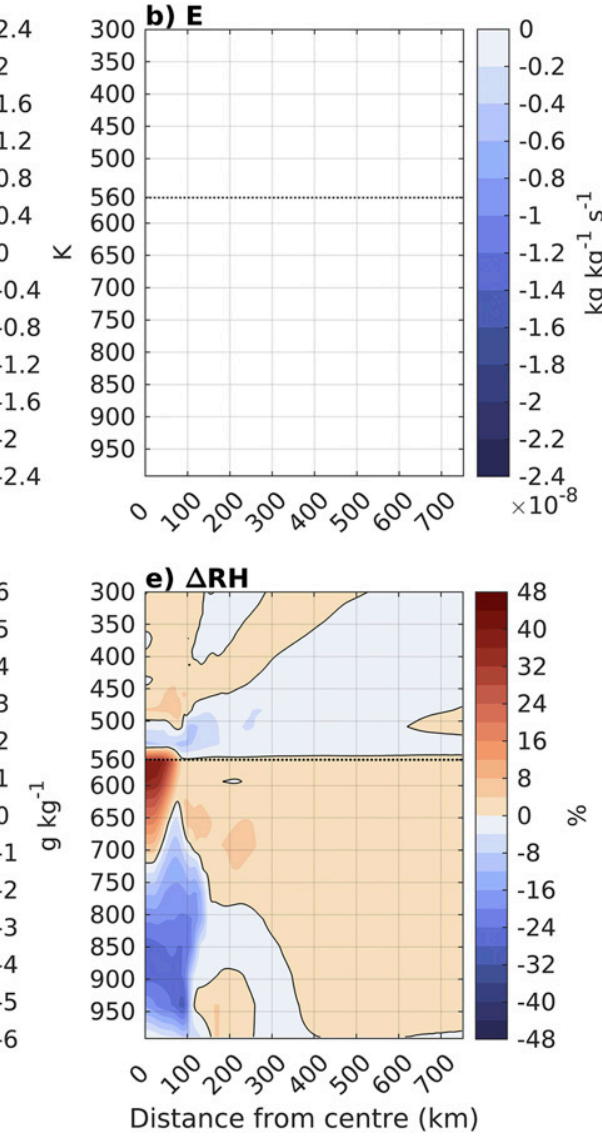

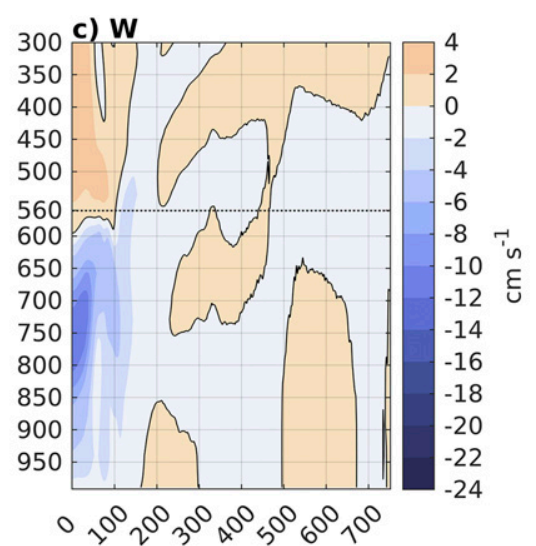

FIG. 5. As in Figs. 2 and 3, but at $10 \mathrm{~h} 40$ min into the control simulation in which precipitation stops at $10 \mathrm{~h}$ into the simulation.

tests were conducted to quantify the sensitivities of the temperature and humidity structures to, first, QR and QNR, second, the microphysical parameterization scheme and, third, the size of the precipitation area.
Figures 7 and 8 show the vertical profiles of horizontal mean temperature, $\mathrm{RH}$, and virtual temperature anomalies in first two aforementioned tests. The horizontal means were calculated as explained in section $3 \mathrm{~b}$.
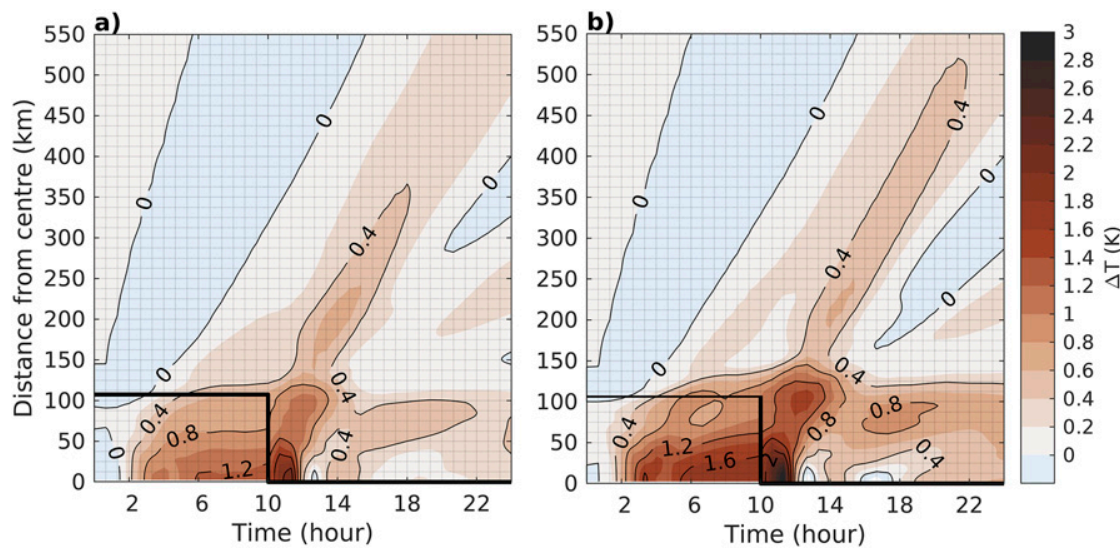

FIG. 6. Temperature anomaly at the model level corresponding to roughly $850 \mathrm{hPa}$ in the (a) control simulation and (b) driest simulation. The $y$ axis shows the distance from the center of the area that contains precipitation. The thick black line represents the edge of the round area containing precipitation. Contours in black are drawn with $0.4-\mathrm{K}$ interval starting from $0 \mathrm{~K}$. 

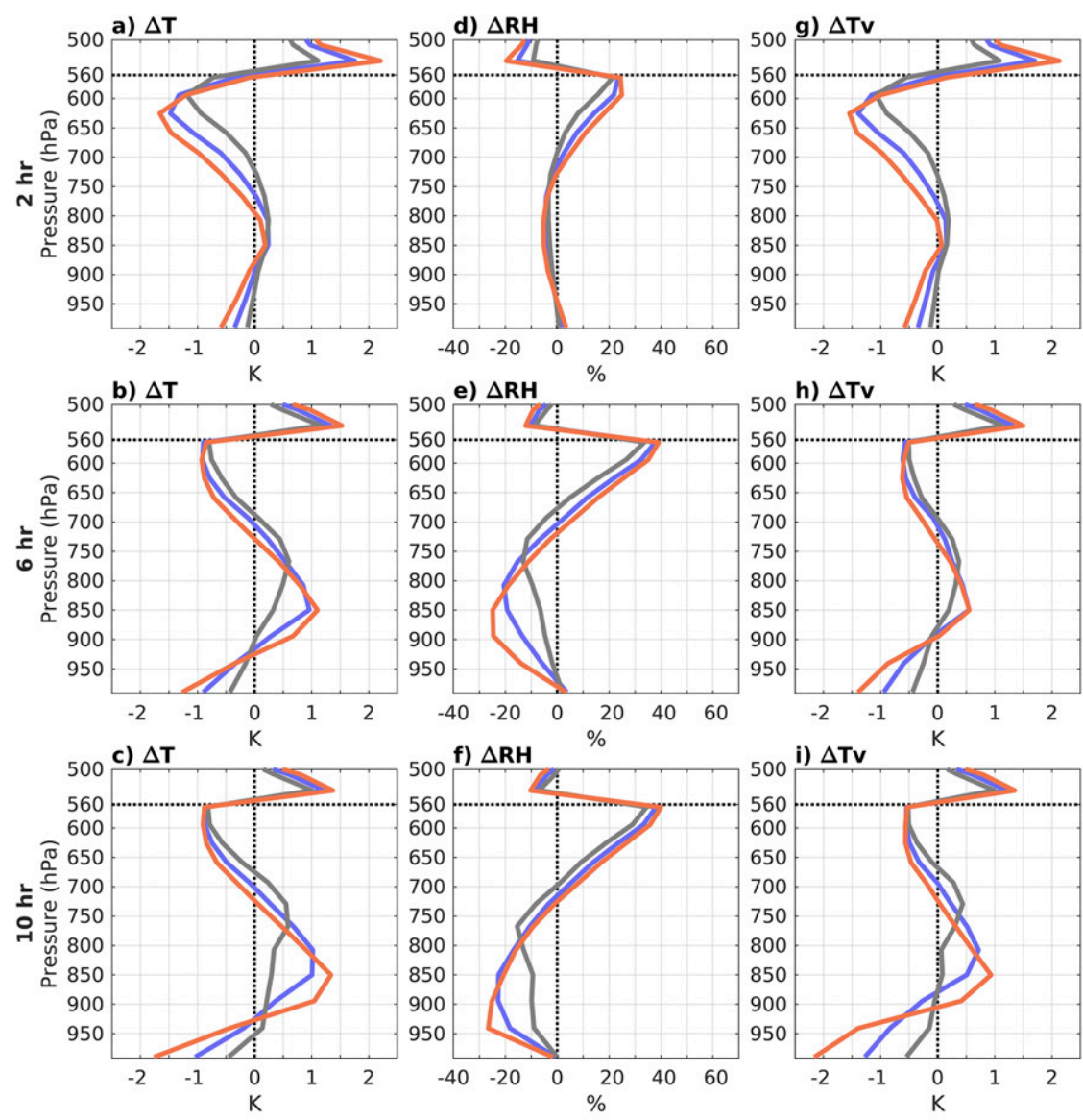

- Control - QR \& QNR decr - QR \& QNR incr

FIG. 7. As in Fig. 4, but for the control simulation (blue) and when QR is decreased by $50 \%$ and QNR by $25 \%$ (gray), and when QR is increased by $50 \%$ and QNR by $25 \%$ (orange) from the values in the control simulation.

As evaporation of precipitation in models is sensitive to the amount and number concentration of the precipitation, the values of QR and QNR of the control simulation were modified in two ways. In the first sensitivity test, QR was decreased by $50 \%$ but QNR only $25 \%$. In the second test, QR was increased by $50 \%$ but QNR only $25 \%$. QR was increased and decreased more than QNR so that lighter precipitation contained relatively fewer large drops and more small drops than heavier precipitation. The larger and smaller QR and QNR values were still within the values occurring in the stratiform region of the idealized squall-line simulations (see section 2).

Decrease in QR and QNR led to weaker evaporation and, as a result, weaker subsidence compared to the control simulation as there was less water to evaporate and cool the air (not shown). As expected, the weaker evaporation and subsidence resulted in smaller horizontal mean $\sim 560-750-\mathrm{hPa}$ cold and $\sim 750-900-\mathrm{hPa}$ warm anomalies as well as in smaller $\sim 560-700-\mathrm{hPa}$ moist and below $\sim 700$-hPa dry anomalies relative to the control simulation (Figs. 7a-f). The positive virtual temperature anomaly between roughly 750 and $900 \mathrm{hPa}$ was also smaller and less robust than in the control simulation (Figs. 7g-i).

Increase in QR and QNR resulted in stronger evaporation and resulting subsidence and, therefore, larger anomalies (Figs. 7a-i). The warm anomaly and the positive virtual temperature anomaly exceeded even 1.2 and $0.9 \mathrm{~K}$, respectively, at roughly $850 \mathrm{hPa}$ when QR and QNR were increased (Figs. 7c,i). Interestingly, decrease in QR and QNR led to a larger difference in the magnitude of the 750-900-hPa warm anomaly relative to the control simulation than when QR and QNR were increased, indicating a nonlinear response (Figs. 7b,c).

Evaporation of stratiform precipitation in numerical models can be sensitive not only to the parameterization of evaporation itself, but also to other related 

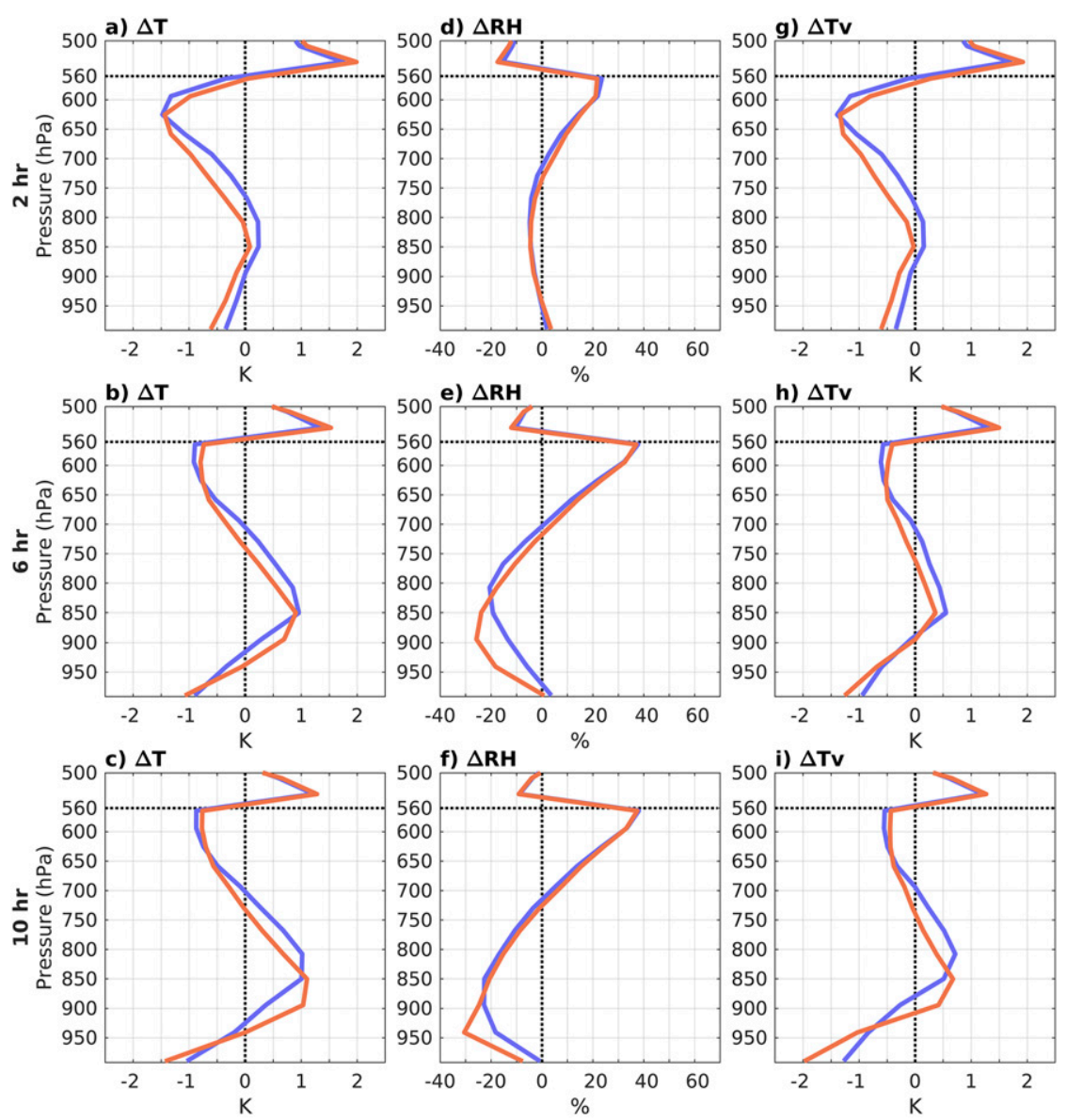

Control, Morrison $=$ Control, Thompson

FIG. 8. As in Figs. 4 and 7, but for the control simulation (blue) and when the microphysical parameterization of Thompson et al. (2008) is used (orange).

microphysical processes. Therefore, the control simulation was repeated using the widely used doublemoment microphysical parameterization scheme of Thompson et al. (2008). In all the other simulations presented here, which used the double-moment microphysics scheme of Morrison et al. (see section 2), ice processes were switched off; however, they were allowed in the simulation using the Thompson scheme as they were not simple to neglect.

The maximum magnitude of the horizontal mean negative and positive temperature and virtual temperature anomalies were not largely sensitive to the choice of microphysics scheme (Figs. 8a-c,g-i), but the negative $\mathrm{RH}$ anomalies were slightly stronger when using the Thompson scheme at 6 and $10 \mathrm{~h}$ (Figs. 8e,f). However, the maximum of the positive temperature and virtual temperature anomaly and the negative $\mathrm{RH}$ anomaly occurred lower when the Thompson scheme was used than when the Morrison scheme was used, especially at
$10 \mathrm{~h}$ (Figs. 8c,f,i). These differences may significantly affect the buoyancy of rising surface air parcels at different levels. The differences may result from different treatment of microphysical processes, for example, sedimentation. A small amount of snow formed above roughly $560 \mathrm{hPa}$ using the Thompson scheme, but the very small difference between the results obtained with the two microphysics schemes above the $650-\mathrm{hPa}$ level in Fig. 8 suggested that this was not the reason for the differences in temperature $\mathrm{RH}$, and virtual temperature anomalies lower down.

We also studied the sensitivity of the temperature and humidity structures to the size of the round area containing precipitation by decreasing its radius to $75 \%$ of the size in the control simulation. Decreasing the area led to qualitatively similar results but with somewhat smaller horizontal mean temperature, virtual temperature, and RH anomalies (not shown). Overall, the temperature, virtual temperature, and $\mathrm{RH}$ anomalies were 


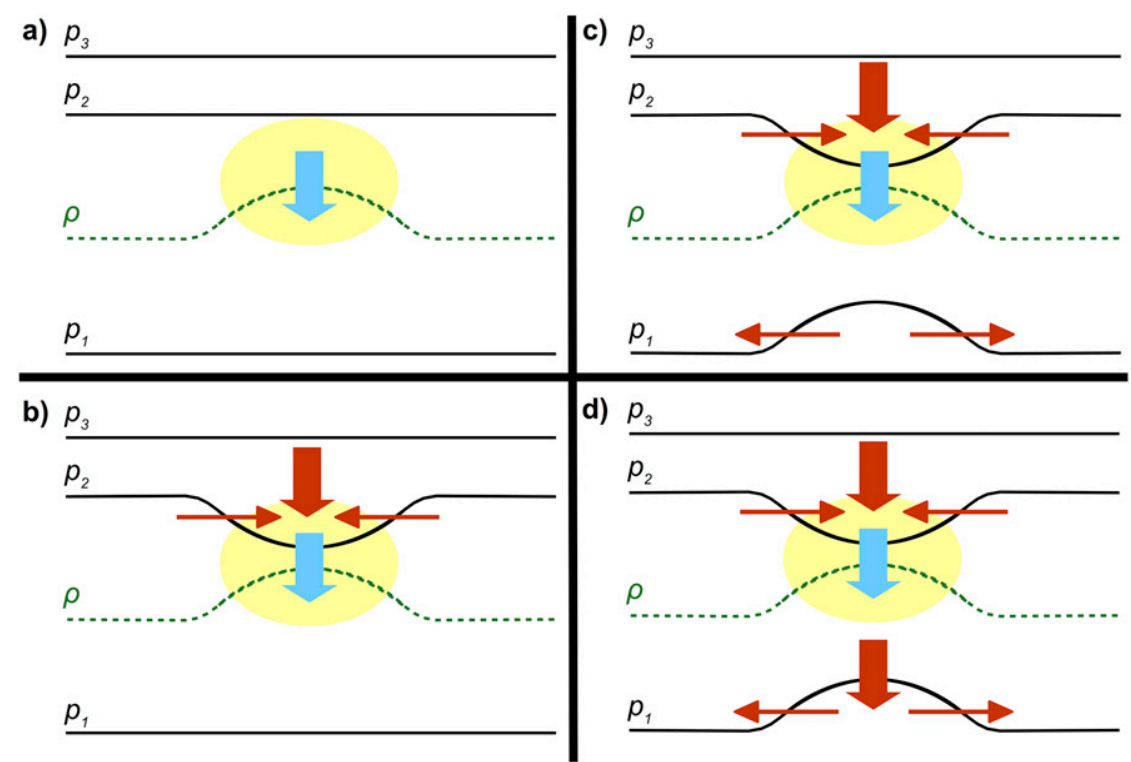

FIG. 9. A simplified illustration of the formation mechanism of the temperature structures seen below and above an anomalously cold layer associated with evaporation of stratiform precipitation (yellow shading). Surfaces of constant pressure are shown in black, so that $p_{1}>p_{2}>p_{3}$ and surfaces of constant density are in green. Blue arrows indicate weak downward motion and red vertical arrows indicate downward motion and adiabatic warming. See text for more details.

somewhat sensitive to the choice of QR and QNR, microphysics scheme and size of precipitation area. However, the main conclusions were largely independent of these choices.

\section{Discussion}

In the simulations, a rather strong mesoscale warm anomaly was observed just above and below the layer that had experienced strong evaporative cooling (Figs. 2b and 3a). Previously, Mapes and Houze (1995) analyzed tropical MCSs and found shallow positive temperature anomalies above and below a layer with diabatic cooling associated with melting. As their results qualitatively resemble the temperature structures seen in our simulations, the formation mechanism of the temperature structures in Mapes and Houze (1995) may be similar to the temperature structures we see in our simulations. The formation of the warm anomaly just above and below the layer of strong evaporation can be understood by using the basic laws of dynamics. This is shown schematically in a step-by-step manner in Fig. 9 and explained below. For simplicity, in Fig. 9, we assume that evaporation occurs in an isolated layer, although in our simulations there is some evaporation in the whole column containing precipitation (Figs. 2 and 3).

Consider an atmosphere that is initially at rest with horizontally homogeneous pressure and density. Evaporation of stratiform precipitation starts to occur (shown by yellow area in Fig. 9) and the associated diabatic cooling increases density (dashed lines in Fig. 9a). Air parcels experience a weak downward acceleration, leading to weak descent (blue arrow in Fig. 9a), as long as the magnitude of the density term is larger than that of the pressure gradient term in the vertical momentum equation [see Eq. (1.9) in Markowski and Richardson 2010]. As a result of the downward motion, the vertical pressure gradient increases where density had increased, leading to restored hydrostatic balance. The negative pressure anomaly leads to horizontal acceleration and convergence (thin red arrows in Fig. 9b) and, therefore, increase of pressure below (Fig. 9c). Note that there is a simultaneous increase of hydrostatic pressure at the surface indicating mass added to the column. Downward motion and adiabatic warming occur above the layer with evaporation (upper thick red arrow in Fig. 9b), as the magnitude of the vertical pressure gradient is smaller than required for hydrostatic balance. Positive pressure anomaly below the evaporation layer leads to horizontal divergence (lower thin red arrows in Fig. 9c). By continuity, there is downward motion and adiabatic warming below the evaporation layer (lower thick red arrow in Fig. 9d). Therefore, in the end, there are warm anomalies above and below the layer with diabatic cooling associated with evaporation.

The larger-scale horizontal temperature structure, after evaporation has occurred for some time, qualitatively 
resembles (but with opposite signs), the response of a Boussinesq, hydrostatic atmosphere at rest to a positiveonly heating typical of tropical MCSs (Mapes 1998). The response to such heating can be understood by considering the dispersion relation for internal gravity waves in the hydrostatic limit (Mapes 1993). The horizontal phase and group velocities are then $c=N / m$, where $N$ is the buoyancy frequency and $m$ is the vertical wavenumber. The hydrostatic limit is not applicable to highly tilted upward-propagating gravity waves but predicts the deeper flow structures quite well (Bretherton and Smolarkiewicz 1989; Nicholls et al. 1991; Mapes 1998). The deeper such structures are (small $m$ ), the faster they propagate away from the heat source. Therefore, the deep spectral components of the heat source are associated with a weak warm anomaly covering a large area, while shallower spectral components are associated with a stronger temperature anomaly in a small area but with greater amplitude (Fig. 1e in Mapes 1998). Similar structures can be seen in our results (e.g., Fig. 3), which also showed a deep structure of weak temperature anomaly covering a larger area (at around $\sim 500 \mathrm{~km}$ ) and shallower structures of stronger temperature anomaly covering a smaller area (within $\sim 200 \mathrm{~km}$ from the center).

It is interesting to compare the observed temperature anomalies of Virman et al. (2018) to the anomalies seen in the simulations of the present study. A notable difference between the observed temperature structures of Virman et al. (2018) and the simulated temperature structures is the presence of the lower-tropospheric warm anomaly just below the layer of strongest evaporation even in the moistest simulation, as the lowertropospheric warm anomaly was not observed over the relatively moist stations in Virman et al. Allowing ice processes and, therefore, melting of ice in the simulations would likely deepen the layer containing a cold anomaly and therefore also influence the magnitude and depth of the warm anomaly. Moreover, Mapes and Houze (1995) showed that the positive-only net heating profile characteristic to MCSs observed over the world's warmest waters, which were relatively close to the moist stations of Virman et al., results in a cold anomaly in the whole lower troposphere below $\sim 500 \mathrm{hPa}$ close to the heat source. Therefore, including the other diabatic processes that constitute the positive-only net heating profile of MCSs, for example, condensation, melting, freezing, and deposition in the convective and stratiform regions, would also affect the anomalies. However, this should be studied by simulating an MCS with all diabatic and radiative processes included. Additionally, the temperature and humidity anomalies in our simulations are, to some degree, affected by the limitations in the microphysics parameterization scheme, most notably the representation of evaporation. Evaporation of precipitation depends on the raindrop size distribution, assumed to be exponential in our simulations (Morrison et al. 2009).

The lower-tropospheric warm anomalies seen in this study, the magnitude of which depends on the low- to midtropospheric humidity, may potentially inhibit the formation of subsequent convection by increasing CIN and thereby decreasing the buoyancy of rising air parcels (Wei et al. 1998). Our simulations show that the warm anomalies propagate to the environment. Moreover, a previous study has shown that practically all precipitating convection in the Tropical Ocean and Global Atmosphere Coupled Ocean-Atmosphere Response Experiment (TOGA COARE) was triggered by the edges of cold pools associated with prior convective downdrafts (Kingsmill and Houze 1999). Torri et al. (2015) studied the mechanisms responsible for such triggering using idealized simulations with no vertical wind shear. They showed that the edges of cold pools are good locations for the eruption of new deep convection not only due to mechanical lifting, but also because air parcels rising from there have relatively large buoyancy. They argued that mechanical lifting dominates near the surface, but the large positive buoyancy allows the air parcels to rise more easily. It is possible that the warm anomalies associated with evaporation of stratiform precipitation, which propagate to the environment, decrease the positive buoyancy of air parcels originating from the edges of cold pools if collocated, thus hindering the triggering of new deep convection. However, as our simulations did not include convective downdrafts, the true potential of the warm anomalies to prevent formation of new convection at the edges of cold pools would require a more detailed study.

The inhibiting effect of dry lower-free-tropospheric air on deep convection is a key element in theories of several convective phenomena of different time and spatial scales, for example, self-aggregation of convection and the MJO. The tendency of convection to selfaggregate has been seen in a number of numerical simulations (see, e.g., Wing et al. 2017). Self-aggregation has been recognized as an important branch of convection research as it has been shown to significantly affect the domain-mean humidity and therefore the model climate (Wing et al. 2017). However, Wing et al. noted that, as self-aggregation is sensitive to the model physics, it is possible that self-aggregation has not yet been robustly characterized. Moreover, it has been observed that the representation of the MJO is also sensitive to the model physics (Kim et al. 2018) and making deep convection more sensitive to environmental moisture 
improved the prediction of MJO in one case (Bechtold 2019). Therefore, it is important to correctly represent the physical processes, for example, convection's dependence on lower-free-tropospheric moisture, in the models used to study and forecast self-aggregation and the MJO. The results of the present study suggest that special attention should be given to realistic representation of stratiform precipitation and its evaporation.

\section{Conclusions}

A recent observation-based study by Virman et al. (2018) showed that lower-tropospheric warm anomalies were observed after precipitation but only over relatively dry regions of tropical oceans. As evaporation is the diabatic process through which lower-freetropospheric moisture can most efficiently affect the vertical structure of temperature, we studied the vertical temperature structure associated with evaporation of stratiform precipitation and its sensitivity to lower-free-tropospheric moisture by conducting several idealized simulation with the WRF Model.

The main conclusions of this study are, first, that evaporation of stratiform precipitation and the resulting subsidence are associated with lower-tropospheric warm anomalies and, second, that the warm anomalies are stronger when the low to midtroposphere is drier in the initial conditions. The simulated warm anomalies are large enough $(\sim 0.7-1 \mathrm{~K}$, depending on initial $\mathrm{RH})$ to potentially prevent subsequent convection by increasing CIN if they would occur in nature (Wei et al. 1998; Raymond et al. 2003). The formation mechanism of the warm anomalies was discussed, using basic laws of fluid dynamics, in section 4 .

The simulated lower-tropospheric warm anomalies associated with stratiform precipitation, especially their magnitudes and vertical scale, and their sensitivities to low- to midtropospheric moisture qualitatively resembled those observed after precipitation over tropical oceans in Virman et al. (2018). However, as these simulations were very idealized a quantitative comparison was not possible.

In the simulations, $2 \mathrm{~h}$ after liquid water was added at roughly $560 \mathrm{hPa}$, evaporation of precipitation and subsidence below resulted in a warm anomaly at $\sim 750$ $900 \mathrm{hPa}$, which is below a $\sim 560-750-\mathrm{hPa}$ cold anomaly. The lower-tropospheric warm anomalies occurred also at varying locations outside of the cylinder containing precipitation and even after precipitation stopped. Therefore, the potential effect of evaporation of stratiform precipitation on subsequent deep convection is not limited to the cylinder containing precipitation nor to the time precipitation occurs. Particularly interesting is the possibility that the warm anomalies would occur above the gust fronts associated with previous convection, as in TOGA COARE it was observed that practically all precipitating convection was triggered by such gust fronts (Kingsmill and Houze 1999). Evaporation of stratiform precipitation and resulting subsidence also produced a dry anomaly below the $\sim 700-\mathrm{hPa}$ level. This suggests that evaporation of stratiform precipitation may also hinder subsequent deep convection by enhancing the effect of entrainment of drier environmental air into cloudy air.

Several sensitivity tests showed that the temperature, $\mathrm{RH}$, and virtual temperature anomalies were somewhat sensitive to the values of QR and QNR, to the doublemoment microphysics scheme and to the size of the precipitation area. However, the main conclusions of this study were insensitive to all of these variables. The layer containing a positive temperature and virtual temperature anomaly was somewhat lower when the Thompson double-moment microphysical parameterization scheme was used instead of the Morrison double-moment scheme, which may have significant impacts on the buoyancy of rising surface air parcels at different levels.

The results of this study imply that special attention should be given to representation of stratiform precipitation and its evaporation in numerical models, as it may partly explain why deep convection is favored by moist air in the lower free-troposphere (Virman et al. 2018). A prerequisite for the realistic representation of evaporation of stratiform precipitation (and therefore of lowertropospheric warm anomalies) is that the amount and horizontal and vertical distribution of stratiform precipitation are correct in numerical models. This requires that vertical and horizontal resolution are sufficient in the models. It is possible that models with a coarse grid may not produce realistic distribution of stratiform precipitation associated with deep convection. Moreover, the formulation and the level of complexity in the microphysical parameterization may have significant impact on the distribution of evaporation of stratiform precipitation. For example, Morrison et al. (2009) showed that the distribution of trailing stratiform precipitation in an idealized squall line was very different in simulations using a single-moment and double-moment scheme due to different rain evaporation rates. Improvements in the representation of evaporation of stratiform precipitation in numerical models has the potential to lead to improvements in, first, weather forecasts and climate projections, as it has been noted that prediction of convective phenomena, for example, the MJO, is sensitive to model physics, particularly to convection's dependence on environmental moisture. Second, the 
improved representation of evaporation may lead to more accurate theories of many convective phenomena, for example, self-aggregation and MJO, as these theories are often formed based on studies with numerical model simulations.

Acknowledgments. M.V. was funded by the Vilho, Yrjö and Kalle Väisälä Foundation. This work was also funded by the Academy of Finland (Project 307331). We thank the CSC-IT Center for Science for their high performance computing services. The simulations were performed with the WRF Model (available at http:// www2.mmm.ucar.edu/wrf/users/). We thank Prof. Brian Mapes and an anonymous reviewer whose suggestions significantly improved this manuscript.

\section{REFERENCES}

Bechtold, P., 2019: Challenges in tropical numerical weather prediction at ECMWF. Current Trends in the Representation of Physical Processes in Weather and Climate Models, Springer, 29-50, https://doi.org/10.1007/978-981-13-3396-5_2.

Bister, M., and K. A. Emanuel, 1997: The genesis of Hurricane Guillermo: TEXMEX analyses and a modeling study. Mon. Wea. Rev., 125, 2662-2682, https://doi.org/10.1175/15200493(1997) $125<2662$ :TGOHGT>2.0.CO;2.

Bretherton, C. S., and P. K. Smolarkiewicz, 1989: Gravity waves, compensating subsidence and detrainment around cumulus clouds. J. Atmos. Sci., 46, 740-759, https://doi.org/10.1175/ 1520-0469(1989)046<0740:GWCSAD > 2.0.CO;2.

— M. E. Peters, and L. E. Back, 2004: Relationships between water vapor path and precipitation over the tropical oceans. J. Climate, 17, 1517-1528, https://doi.org/10.1175/ 1520-0442(2004)017<1517:RBWVPA > 2.0.CO;2.

Brown, R. G., and C. Zhang, 1997: Variability of midtropospheric moisture and its effect on cloud-top height distribution during TOGA COARE. J. Atmos. Sci., 54, 2760-2774, https://doi.org/ 10.1175/1520-0469(1997)054<2760:VOMMAI >2.0.CO;2.

Derbyshire, S. H., I. Beau, P. Bechtold, J.-Y. Grandpeix, J.-M. Piriou, J.-L. Redelsperger, and P. M. M. Soares, 2004: Sensitivity of moist convection to environmental humidity. Quart. J. Roy. Meteor. Soc., 130, 3055-3079, https://doi.org/ 10.1256/qj.03.130.

Dunion, J. P., 2011: Rewriting the climatology of the tropical North Atlantic and Caribbean Sea atmosphere. J. Climate, 24, 893 908, https://doi.org/10.1175/2010JCLI3496.1.

Emanuel, K. A., 1994: Atmospheric Convection. Vol. 580. Oxford University Press, $580 \mathrm{pp}$.

Hirons, L. C., P. Inness, F. Vitart, and P. Bechtold, 2013: Understanding advances in the simulation of intraseasonal variability in the ECMWF model. Part II: The application of process-based diagnostics. Quart. J. Roy. Meteor. Soc., 139, 1427-1444, https://doi.org/10.1002/qj.2059.

Holloway, C. E., and J. D. Neelin, 2009: Moisture vertical structure, column water vapor, and tropical deep convection. J. Atmos. Sci., 66, 1665-1683, https://doi.org/10.1175/2008JAS2806.1.

Hong, S.-Y., Y. Noh, and J. Dudhia, 2006: A new vertical diffusion package with an explicit treatment of entrainment processes. Mon. Wea. Rev., 134, 2318-2341, https://doi.org/10.1175/ MWR3199.1.
Houze, R. A., Jr., 1982: Cloud clusters and large-scale vertical motions in the tropics. J. Meteor. Soc. Japan, 60, 396-410, https://doi.org/10.2151/jmsj1965.60.1_396.

1993: Cloud Dynamics. Vol. 573. Academic Press, 573 pp. ,2018: 100 years of research on mesoscale convective systems. A Century of Progress in Atmospheric and Related Sciences: Celebrating the American Meteorological Society Centennial, Meteor. Monogr., No. 59, Amer. Meteor. Soc., https://doi.org/ 10.1175/AMSMONOGRAPHS-D-18-0001.1.

Jiménez, P. A., J. Dudhia, J. F. González-Rouco, J. Navarro, J. P. Montávez, and E. García-Bustamante, 2012: A revised scheme for the WRF surface layer formulation. Mon. Wea. Rev., 140, 898-918, https://doi.org/10.1175/MWR-D-1100056.1 .

Johnson, R. H., 1986: Lower-tropospheric warming and drying in tropical mesoscale convective systems: Implications for the problem of cumulus parameterization. J. Meteor. Soc. Japan, 64, 721-726, https://doi.org/10.2151/jmsj1965.64.5_721.

—, 2001: Surface mesohighs and mesolows. Bull. Amer. Meteor. Soc., 82, 13-32, https://doi.org/10.1175/1520-0477(2001)082<0013: SMAM $>2.3 . \mathrm{CO} ; 2$

— , and D. C. Kriete, 1982: Thermodynamic and circulation characteristics, of winter monsoon tropical mesoscale convection. Mon. Wea. Rev., 110, 1898-1911, https://doi.org/ 10.1175/1520-0493(1982)110<1898:TACCOW > 2.0.CO;2.

Kim, D., A. H. Sobel, E. D. Maloney, D. M. Frierson, and I.-S. Kang, 2011: A systematic relationship between intraseasonal variability and mean state bias in AGCM simulations. J. Climate, 24, 5506-5520, https://doi.org/10.1175/2011JCLI4177.1.

Kim, H., F. Vitart, and D. E. Waliser, 2018: Prediction of the Madden-Julian oscillation: A review. J. Climate, 31, 94259443, https://doi.org/10.1175/JCLI-D-18-0210.1.

Kingsmill, D. E., and R. A. Houze Jr., 1999: Thermodynamic characteristics of air flowing into and out of precipitating convection over the west Pacific warm pool. Quart. J. Roy. Meteor. Soc., 125, 1209-1229, https://doi.org/10.1002/qj.1999.49712555606.

Mapes, B. E., 1993: Gregarious tropical convection. J. Atmos. Sci., 50, 2026-2037, https://doi.org/10.1175/1520-0469(1993) $050<2026$ :GTC $>2.0$. CO 2 .

, 1998: The large-scale part of tropical mesoscale convective system circulations: A linear vertical spectral band model. J. Meteor. Soc. Japan, 76, 29-55, https://doi.org/10.2151/ jmsj1965.76.1_29.

, and R. A. Houze Jr., 1995: Diabatic divergence profiles in western Pacific mesoscale convective systems. J. Atmos. Sci., 52, 1807-1828, https://doi.org/10.1175/1520-0469(1995)052<1807: DDPIWP $>2.0 . \mathrm{CO} ; 2$.

Markowski, P., and Y. Richardson, 2010: Mesoscale Meteorology in Midlatitudes. John Wiley and Sons, 430 pp., https://doi.org/ 10.1002/9780470682104.ch2.

Mohr, K. I., and E. J. Zipser, 1996: Mesoscale convective systems defined by their $85-\mathrm{GHz}$ ice scattering signature: Size and intensity comparison over tropical oceans and continents. Mon. Wea. Rev., 124, 2417-2437, https://doi.org/10.1175/ 1520-0493(1996)124<2417:MCSDBT>2.0.CO;2.

Morrison, H., G. Thompson, and V. Tatarskii, 2009: Impact of cloud microphysics on the development of trailing stratiform precipitation in a simulated squall line: Comparison of oneand two-moment schemes. Mon. Wea. Rev., 137, 991-1007, https://doi.org/10.1175/2008MWR2556.1.

Neelin, J. D., O. Peters, and K. Hales, 2009: The transition to strong convection. J. Atmos. Sci., 66, 2367-2384, https://doi.org/ 10.1175/2009JAS2962.1. 
Nicholls, M. E., R. A. Pielke, and W. R. Cotton, 1991: Thermally forced gravity waves in an atmosphere at rest. J. Atmos. Sci., 48, 1869-1884, https://doi.org/10.1175/1520-0469(1991)048<1869: TFGWIA $>2.0 . \mathrm{CO} ; 2$.

Peters, O., and J. D. Neelin, 2006: Critical phenomena in atmospheric precipitation. Nat. Phys., 2, 393-396, https://doi.org/ 10.1038/nphys314.

Raymond, D. J., 1995: Regulation of moist convection over the west Pacific warm pool. J. Atmos. Sci., 52, 3945-3959, https://doi.org/ 10.1175/1520-0469(1995)052<3945:ROMCOT>2.0.CO;2.

, G. B. Raga, C. S. Bretherton, J. Molinari, C. López-Carrillo, and Z. Fuchs, 2003: Convective forcing in the intertropical convergence zone of the eastern Pacific. J. Atmos. Sci., 60, 2064-2082, https://doi.org/10.1175/1520-0469(2003)060<2064: CFITIC $>2.0 . \mathrm{CO} ; 2$.

Rickenbach, T. M., and S. A. Rutledge, 1998: Convection in TOGA COARE: Horizontal scale, morphology, and rainfall production. J. Atmos. Sci., 55, 2715-2729, https://doi.org/10.1175/ 1520-0469(1998)055<2715:CITCHS > 2.0.CO;2.

Schiro, K. A., J. D. Neelin, D. K. Adams, and B. R. Lintner, 2016: Deep convection and column water vapor over tropical land versus tropical ocean: A comparison between the Amazon and the tropical western Pacific. J. Atmos. Sci., 73, 4043-4063, https://doi.org/10.1175/JAS-D-16-0119.1.

Sherwood, S. C., 1999: Convective precursors and predictability in the tropical western Pacific. Mon. Wea. Rev., 127, 2977-2991, https://doi.org/10.1175/1520-0493(1999)127<2977: CPAPIT $>2.0 . \mathrm{CO} ; 2$.

Skamarock, W. C., and Coauthors, 2008: A description of the Advanced Research WRF version 3. NCAR Tech. Note NCAR/TN-475+STR, 113 pp., https://doi.org/10.5065/ D68S4MVH.

Sobel, A. H., S. E. Yuter, C. S. Bretherton, and G. N. Kiladis, 2004: Large-scale meteorology and deep convection during TRMM
KWAJEX. Mon. Wea. Rev., 132, 422-444, https://doi.org/ 10.1175/1520-0493(2004)132<0422:LMADCD>2.0.CO;2.

Thompson, G., P. R. Field, R. M. Rasmussen, and W. D. Hall, 2008: Explicit forecasts of winter precipitation using an improved bulk microphysics scheme. Part II: Implementation of a new snow parameterization. Mon. Wea. Rev., 136, 5095-5115, https://doi.org/10.1175/2008MWR2387.1.

Tompkins, A. M., 2001: Organization of tropical convection in low vertical wind shears: The role of water vapor. J. Atmos. Sci., 58, 529-545, https://doi.org/10.1175/1520-0469(2001) $058<0529$ :OOTCIL $>2.0$. CO $;$.

Torri, G., Z. Kuang, and Y. Tian, 2015: Mechanisms for convection triggering by cold pools. Geophys. Res. Lett., 42, 1943-1950, https://doi.org/10.1002/2015GL063227.

Virman, M., M. Bister, V. A. Sinclair, H. Järvinen, and J. Räisänen, 2018: A new mechanism for the dependence of tropical convection on free-tropospheric humidity. Geophys. Res. Lett., $\mathbf{4 5}$, 2516-2523, https://doi.org/10.1002/2018GL077032.

Wei, D., A. M. Blyth, and D. J. Raymond, 1998: Buoyancy of convective clouds in TOGA COARE. J. Atmos. Sci., 55, 3381-3391, https:// doi.org/10.1175/1520-0469(1998)055<3381:BOCCIT>2.0.CO;2.

Wing, A. A., K. Emanuel, C. E. Holloway, and C. Muller, 2017: Convective self-aggregation in numerical simulations: A review. Shallow Clouds, Water Vapor, Circulation, and Climate Sensitivity, Space Sciences Series of ISSI, Vol. 65, Springer, 125, https://doi.org/10.1007/978-3-319-77273-8_1.

Zipser, E. J., 1969: The role of organized unsaturated convective downdrafts in the structure and rapid decay of an equatorial disturbance. J. Appl. Meteor., 8, 799-814, https://doi.org/ 10.1175/1520-0450(1969)008<0799:TROOUC>2.0.CO;2.

__ 1977: Mesoscale and convective-scale downdrafts as distinct components of squall-line structure. Mon. Wea. Rev., 105, 1568-1589, https://doi.org/10.1175/1520-0493(1977)105<1568: MACDAD $>2.0 . \mathrm{CO} ; 2$. 